\title{
CONSUMO DE ÁGUA EM LAVOURAS DE ARROZ IRRIGADAS EM SISTEMA COLETIVO
}

\section{WATER CONSUMPTION IN IRRIGATED RICE LAVORS IN COLLECTIVE SYSTEM}

\begin{abstract}
Álvaro José Back
Engenheiro Agrônomo, Dr. em Engenharia, pesquisador da Empresa de Pesquisa Agropecuária e Extensão Rural de Santa Catarina (EPAGRI), estação experimental de Urussanga, rodovia SC 108, km 1563, Caixa Postal 49, Urussanga, SC, CEP 88840-000. E-mail: ajb@epagri.sc.gov.br

\section{Marcio Carlos Just}

Engenheiro agrimensor, Mestre em Ciências Ambientais, Professor do Curso de Engenharia de Agrimensura da UNESC. E-mail: mcj@unesc.net
\end{abstract}

\section{RESUMO}

Este trabalho teve como objetivo avaliar o consumo de água e a eficiência da irrigação em um sistema coletivo de irrigação e drenagem de arroz irrigado de forma a fornecer informações para a gestão de recursos hídricos e a diminuição dos conflitos pelo uso da água. Foi realizado o monitoramento hidrológico da área da Associação de Irrigação e Drenagem Santo Isidoro (Adisi) durante o período de irrigação das safras de 2008/2009 e 2009/2010. Esta Associação localiza-se nos municípios de Nova Veneza e Forquilhinha, Sul de Santa Catarina, contendo área de 2770 hectares cultivados com arroz no sistema de plantio pré-germinado. Foram instaladas estações hidrológicas para o monitoramento e telemetria horária da chuva e do nível de água. No canal de irrigação foi instalada uma calha Parshall com largura de garganta de $152 \mathrm{~cm}$ e nos dois canais de drenagem foram instaladas calhas CTR com largura da garganta (W) de $60 \mathrm{~cm}$. Nos dois anos, durante os 181 dias de irrigação, observou-se as vazões médias de irrigação de $1,707 \mathrm{~m}^{3} \mathrm{~s}^{-1}$ e $1,861 \mathrm{~m}^{3} \mathrm{~s}^{-1}$, e vazões de médias de drenagem de $0,75 \mathrm{~m}^{3} \mathrm{~s}^{-1}$ e $1,033 \mathrm{~m}^{3} \mathrm{~s}^{-1}$, correspondendo a eficiência de irrigação de 55 e $45 \%$ respectivamente. O consumo de água foi de $5030 \mathrm{~m}^{3} \mathrm{ha}^{-1} \mathrm{e} 4753 \mathrm{~m}^{3}$ ha1

Palavras-chave irrigação. recursos hídricos. eficiência de irrigação.

\begin{abstract}
The objective of this study was to evaluate water consumption and irrigation efficiency in a collective system of irrigation and drainage of irrigated rice in order to provide information for the management of water resources and the reduction of conflicts over water use. The hydrological monitoring of the area of the Santo Isidoro Irrigation and Drainage Association (Adisi) was carried out during the irrigation period of the 2008/2009 and 2009/2010 harvests. This Association is located in the municipalities of Nova Veneza and Forquilhinha, South of Santa Catarina, Brazil, containing an area of 2770 hectares cultivated with rice in the system of pre-germinated planting. Hydrological stations were installed for the monitoring and hourly telemetry of rainfall and water level. In the irrigation channel a Parshall gutter with a throat width of $152 \mathrm{~cm}$ was installed and $60 \mathrm{~cm}$ wide throat width (W) was installed in the two drainage channels. In the two years, during the 181 days of irrigation, the average flow rates of $1,707 \mathrm{~m}^{3} \mathrm{~s}^{-1}$ and $1,861 \mathrm{~m}^{3} \mathrm{~s}^{-1}$ were observed, and drainage averages of $0.75 \mathrm{~m}^{3} \mathrm{~s}^{-1}$ and $1,033 \mathrm{~m}^{3} \mathrm{~s}^{-1}$, corresponding to the irrigation efficiency of 55 and $45 \%$, respectively. The water consumption was $5030 \mathrm{~m}^{3} \mathrm{ha}^{-1}$ and $4753 \mathrm{~m}^{3} \mathrm{ha}^{-1}$.
\end{abstract}

Keywords: irrigation. water resources. irrigation efficiency. 


\section{Introdução}

A água é um elemento essencial para avida, sendo de grande importância para o desenvolvimento social, econômico e cultura de uma região. A água é utilizada para diversos usos, entre os quais se destacam o consumo humano, irrigação, na indústria.

O crescimento populacional e aumento da demanda de alimentos vêm estimulando o uso da irrigação. Atualmente, mais de $50 \%$ da população mundial depende de produtos irrigados. A agricultura irrigada é a atividade humana que demanda maior quantidade total de água. Em termos mundiais, estima-se que esse uso responda por cerca de $80 \%$ das derivações de água; no Brasil, esse valor supera os 60\% (FGV, 1998).

A irrigação é exigente em termos de qualidade da água e, nos casos de grandes projetos, implica obras de regularização de vazões, ou seja, barragens, que interferem no regime fluvial dos cursos d'água e sobre o meio ambiente. A irrigação é uma forma de uso consuntivo da água, isto é, parte da água utilizada para este fim não retorna ao seu curso original, havendo redução efetiva da disponibilidade do manancial.

A crescente demanda pela água para satisfazer os múltiplos usos associado a variabilidade sazonal e espacial da disponibilidade hídrica, caraterizado a situação de escassez hídrica tem contribuído para o aumento dos conflitos entre os usuários. No Sul do país, a enorme demanda de água para irrigação de arrozais é o caso mais visível. O desenvolvimento e crescimento da região Sul de Santa Catarina foi decorrente da atividade de mineração de carvão. Essa atividade causou profundos impactos ambientais, principalmente na qualidade dos recursos hídricos. Atualmente as atividades agrícolas e a indústria também contribuíram para a poluição das águas. Na bacia do Rio Araranguá existem conflitos pelo uso da água, principalmente entre a irrigação das áreas de cultivo do arroz e o abastecimento público, que são agravados nas épocas de estiagens (ROSSO, 2007).

Para atendimento da demanda crescente são construídas barragens para captação e armazenamento de água. Assim os reservatórios têm sido utilizados para múltiplas finalidades ao longo da história da humanidade: produção de alimentos (pesca e piscicultura), abastecimento de água, hidroeletricidade, recreação, água para irrigação, turismo e navegação (NOGUEIRA et al., 2006).

Para a gestão dos recursos hídricos e diminuição dos conflitos é fundamental que se conheça as disponibilidades de água e demandas de cada um dos usos previstos. A demanda para o abastecimento urbano é razoavelmente bem conhecida, uma vez que existem registros históricos de consumo de água. No caso da água usada rizicultura ainda não há informações 
precisas do real consumo de água. Tabbal et al. (2002) no entanto, ressaltam que devido ao crescente aumento da demanda de água pela população é necessário aumentar a eficiência de uso da água na irrigação.

O cultivo do arroz irrigado nos estados do Rio Grande do Sul e Santa Catarina corresponde a $60 \%$ da produção nacional e é de grande importância sócia econômica para diversos municípios desses estados (EMBRAPA, 2005). O Rio Grande do Sul se destaca como o maior produtor nacional, sendo responsável por mais de $61 \%$ do total produzido no Brasil, seguido por Santa Catarina com produção de 8 a 9\%. Esse grande volume produzido nos dois estados sulinos, totalizando cerca de $70 \%$, é considerado estabilizador para o mercado brasileiro e garante o suprimento desse cereal à população brasileira (IRGA, 2014).

O sistema de plantio pré-germinado é adotado em mais de $96 \%$ da área de plantio do estado de Santa Catarina (Freitas, 2009) e vem ganhando relevância no Rio Grande do Sul (IRGA, 2007). Esse sistema tem como vantagens em relação aos sistemas tradicionais de irrigação a redução da incidência de plantas daninhas, o efeito termo-regulador, a maior disponibilidade de nutrientes no solo para as plantas de arroz e a redução de mão-de-obra. Apesar dessas vantagens, por ter maior período de irrigação contínua, apresenta como desvantagem em relação a outros sistemas de cultivo de arroz irrigado, o fato de resultar em maior consumo de água.

No sistema de plantio pré-germinado a área de plantio deve ser nivelada (sistematizada) e preparada adequadamente para o recebimento da semente pré-germinada. $\mathrm{O}$ alagamento da área se inicia durante a fase de preparo do solo, aproximadamente 20 dias antes da semeadura de sementes pré-germinadas. Posteriormente, a lâmina de água é elevada até atingir 5 a $10 \mathrm{~cm}$ de altura, realizando-se então a semeadura (SOSBAI, 2014). A prática normalmente adotada é a retirada em 01 a 03 dias, deixando o solo em estado de saturação permanente (solo encharcado), durante 03 a 06 dias, EMBRAPA (2005). Atualmente pesquisas estão sendo desenvolvidas para a manutenção da lâmina de água permanente a partir da semeadura. Os resultados evidenciam que as produtividades médias obtidas foram semelhantes nos dois processos, independente da cultivar testada (SANTOS et al., 2007). Fernandes (2004) comparando o sistema pré-germinado com várias trocas de água com o sistema de manejo de água continuo em duas unidades experimentais de Santa Catarina observou aumento na produtividade e redução de entorno de $40 \%$ no consumo de água no sistema de manejo de água continuo. Segundo IRGA (2014) no sistema pre-germinado estima-se que venha sendo utilizado, atualmente, um volume de água médio de 8 a 10 mil 
$\mathrm{m}^{3} \mathrm{ha}^{-1}$ (vazão de 1,0 a $1,4 \mathrm{Ls}^{-1} \mathrm{ha}^{-1}$ ), para um período médio de irrigação de 80 a 100 dias. Solos arenosos e com maior declividade normalmente requerem maior quantidade de água. Da mesma forma, a demanda hídrica é maior em anos com temperaturas elevadas e umidade relativa do ar baixa ou com baixa precipitação.

A quantidade de água exigida para o cultivo de arroz é o somatório da água necessária para saturação do solo, formação da lâmina, reposição das perdas por evapotranspiração, constituição dos tecidos da planta e compensação de todas as perdas no sistema de condução e distribuição de água na lavoura. A evapotranspiração é a componente de maior importância na demanda hídrica do arroz irrigado (MOTTA et al. 1990), sendo influenciado pelas condições meteorológicas. Experimentos realizados por Rosso (2007) na Região Sul de Santa Catarina determinaram a evapotranspiração durante o ciclo de 140 dias, encontrando um valor de 883 $\mathrm{mm}$, correspondendo à média de $6,3 \mathrm{~mm} \mathrm{dia}^{-1}$. Stone (2002) descreve os componentes do requerimento de água em sistemas de produção de arroz e identifica como importantes fontes de perda de água do sistema usada no preparo do solo, o fluxo lateral e a perda por percolação.

Em Santa Catarina existem em torno de 130 mil ha de área cultivada com arroz irrigado, sendo a grande maioria em pequenas propriedades. Somente na bacia do rio Ararángua são cultivados aproximadamente 55 mil ha com o arroz irrigado. Nessa bacia existem conflitos pelo uso dos recursos hídricos na irrigação e no abastecimento urbano e também conflitos entre os irrigantes, sendo agravado nos anos com ocorrências de estiagens. Outro agravante para os conflitos pelo uso da água é a qualidade dos recursos hídricos da região, que na maioria se encontram comprometidos para o consumo e também para irrigação devido a poluição pela atividade de mineração do carvão (ROSSO, 2007). Segundo Irga (2014), atualmente a otimização do uso da água pela lavoura de arroz constitui-se em questão prioritária do setor orizícola, que busca alternativas de manejo técnica, econômica e ambientalmente sustentáveis.

A maior parte das áreas são irrigadas por sistemas coletivos de captação e condução de água, que são administrados por associações formais de pequenos agricultores. Apesar da tradição na irrigação da cultura do arroz, o manejo da irrigação e a distribuição da água são realizados de forma empírica, ineficiente, baseado unicamente na oferta da água. Esses sistemas de captação foram construídos sem a preocupação de colocação de estruturas que possibilitem medições e controle da quantidade e qualidade da água de irrigação. A gestão de recursos hídricos é um instrumento necessário para diminuir os conflitos, e para a sua 
aplicação requer o conhecimento dos volumes de água existentes e também das demandas dos diversos setores, entre os quais a necessidade de água usada para a irrigação da cultura do arroz. Ladwig et al. (2017) apresentam estudo sobre a cobrança do uso da água na irrigação como instrumeto de gestão hídrica.

Este trabalho tem como objetivo avaliar o consumo de água e a eficiência de um sistemas coletivo de irrigação e drenagem da cultura do arroz cultivado no sistema prégerminado na região Sul de Santa Catarina de forma a fornecer subsídios para a gestão dos recursos hídricos e a diminuição dos conflitos pelo uso da água.

\section{Material e métodos}

A pesquisa foi realizada na área da Associação de Irrigação e Drenagem Santo Isidoro (Adisi) localizada nos municípios de Nova Veneza e Forquilhinha, no Sul de Santa Catarina (Figura 1). Esta Associação, fundada em 1984 com a finalidade de disciplinar, manter e regular a distribuição de água canalizada aos produtores de arroz, possui atualmente 246 sócios cultivando 2770 ha de arroz irrigado. A água utilizada na irrigação é derivada por gravidade do Rio São Bento, em uma única entrada, e distribuída por sistemas ramificados de canais aos diversos produtores. O sistema de canais, com aproximadamente $115 \mathrm{~km}$ de extensão, tem função de irrigação e drenagem dos excessos, de forma a evitar perdas de água ao longo da área irrigada, sendo que na parte inferior os canais convergem para duas saídas.

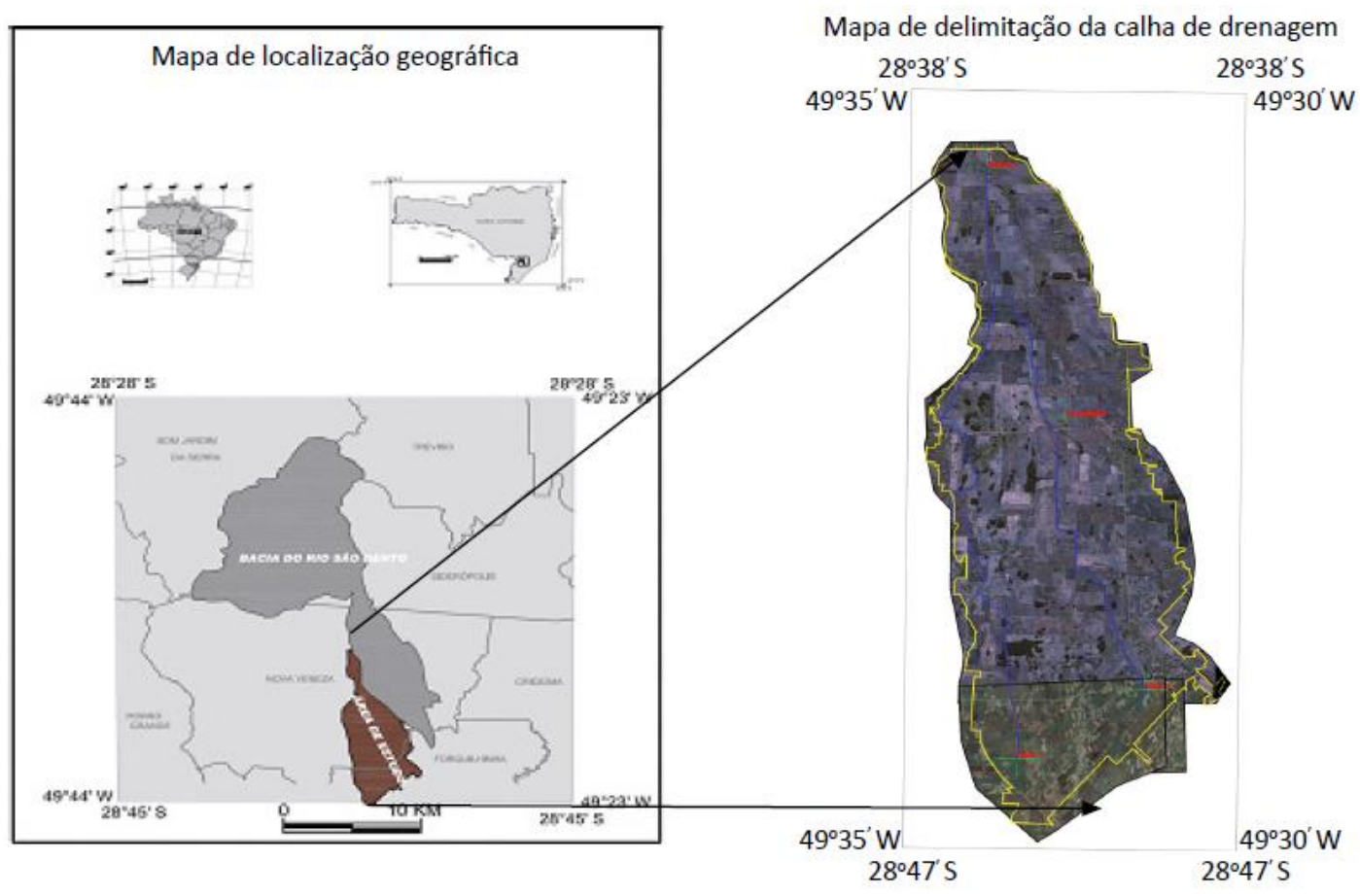


Figura 1. Localização da área de estudo.

Para o monitoramento da vazão foram instaladas estações telemétricas com sensores de nível no canal de entrada e também nos canais de saída (Figura 2). Em cada estação telemétrica foi colocado um sensor de nível e um pluviógrafo para registrar e transmitir dados em intervalos horários. A vazão no canal de entrada foi monitorada com uma calha Parshall com largura de garganta $(\mathrm{W})$ de 1,524 m e nas duas estações de saída foram construídas calhas do tipo CTR, com largura de garganta (W) 60,0 cm e comprimento de 180,0 cm, conforme descrito em Back (2015). A estimativa da evapotranspiração foi realizada com base nos dados de evaporação do Tanque Classe A da estação climatológica da Barragem do Rio São Bento, adotando-se o coeficiente Kc igual a 1,2 para todo o período de cultivo. Para o monitoramento da precipitação, além dos pluviógrafos das estações telemétricas, foram utilizados dados de observação de um pluviômetro instalado numa propriedade localizada aproximadamente ao centro da área irrigada e do pluviômetro da estação climatológica da Barragem do Rio São Bento.

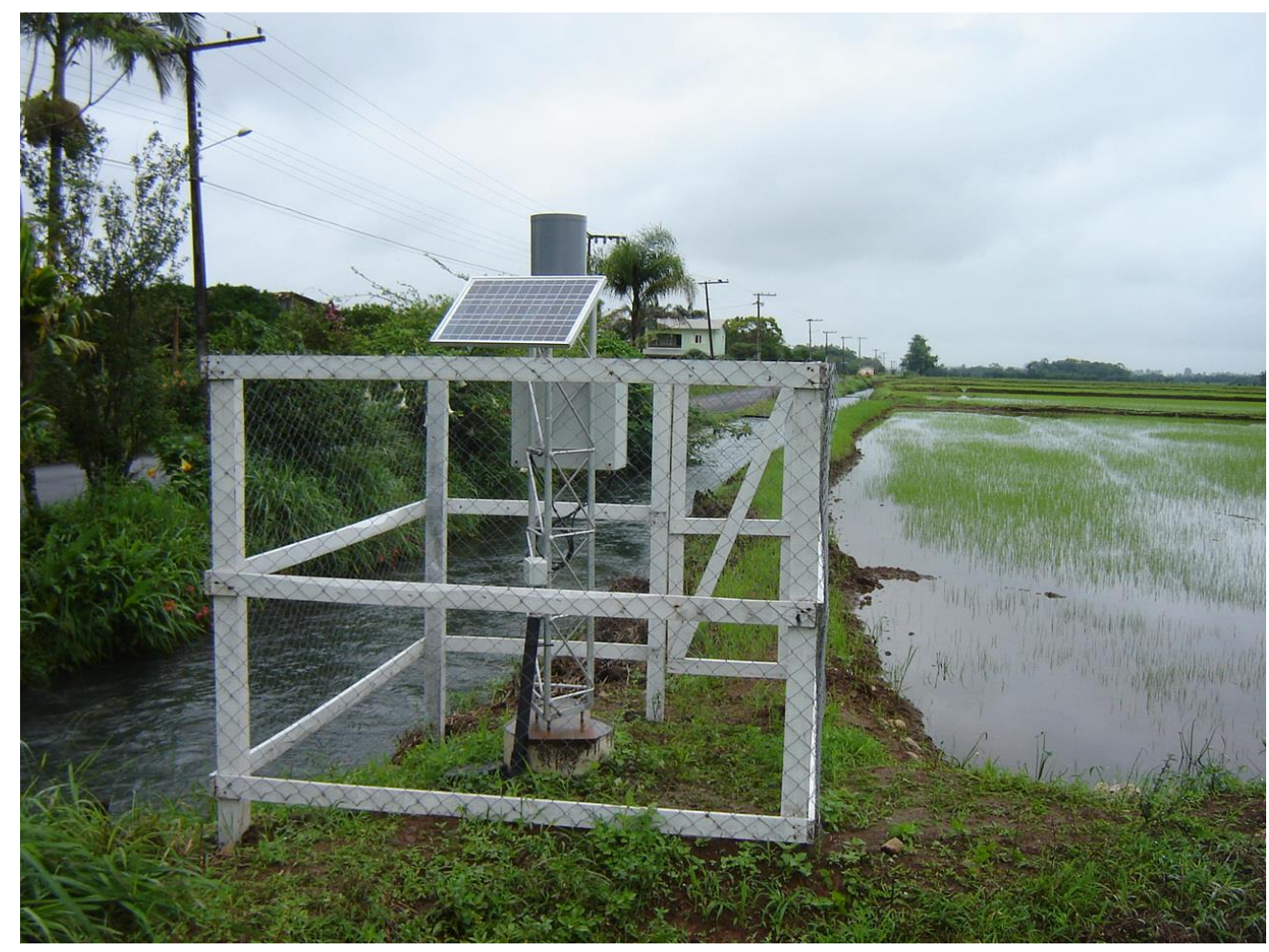

Figura 1. Estação de Monitoramento da vazão de Entrada. 


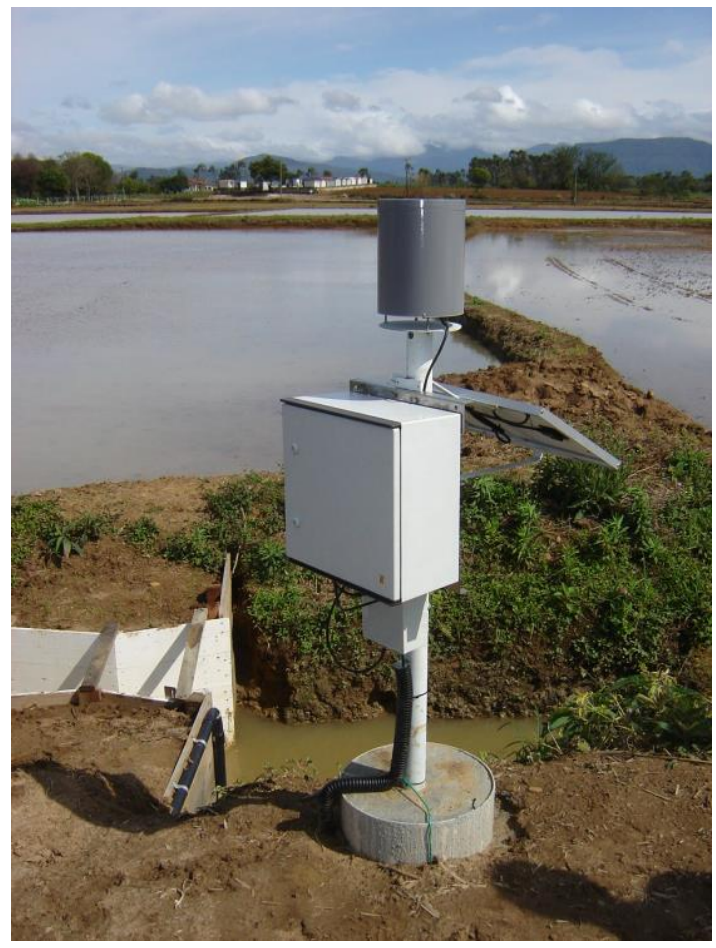

Figura 2. Estação de monitoramento de vazão de saída

\section{Resultados e discussão}

Nas tabelas 1 e 2 constam os resumos do monitoramento hidrológico com o consumo de água para as safras 2008/09 e 2009/10, respectivamente. No ano de 2008/09 a vazão média foi de irrigação foi de $1,707 \mathrm{~m}^{3} \mathrm{~s}^{-1}$ e vazão média da drenagem foi de $0,775 \mathrm{~m}^{3} \mathrm{~s}^{-1}$. No ano de $2009 / 10$ esses valores foram respectivamente de $1,861 \mathrm{~m}^{3} \mathrm{~s}^{-1}$ e $1,033 \mathrm{~m}^{3} \mathrm{~s}^{-1}$. Esses altos valores de vazão de drenagem em parte são devidos aos excessos de precipitação que ocorreram na área da pesquisa, mas também pela falta de controle da irrigação. Como foram anos com precipitação acima da média, a vazão do rio São Bento atendia a demanda dos agricultores, não houve um controle mais rigoroso da irrigação. Embora exista no canal de derivação uma comporta que permite controlar a vazão de irrigação, manteve-se vazão praticamente todo o período acima de $1,500 \mathrm{~m}^{3} \mathrm{~s}^{-1}$, com redução apenas nos dias com precipitação intensa que provocaram alagamentos na área. Também ressalta-se que a água excedente atende a agricultores não associados a Adisi que se localizam em áreas à jusante. Embora a Adisi não tenha compromisso de atendê-los, nos momentos de excessos hídricos verifica-se uma cortesia liberando esse excedente. Nas ocasiões que a demanda de água é maior que a disponibilidade, os irrigantes localizados à jusante da tomada de água da Adisi reclamam pela redução da vazão derivada pela Adisi, refletindo na diminuição das vazões de drenagem e no aumento a eficiência da irrigação. Também a instituição da cobrança pela 
utilização dos recursos hídricos certamente implicará em maior controle da irrigação, diminuindo os valores de vazão de drenagem. O sistema de monitoramento com telemetria permite acompanhamento em tempo real no computador do administrador do sistema esse comentário foi feito mais abaixo também. Isso possibilita aumentar a rapidez na tomada de decisão de fechamento ou abertura da comporta de derivação, melhorando a eficiência do sistema de irrigação.

Tabela 1. Dados do consumo de água na área da Adisi na safra 2008/2009.

\begin{tabular}{|c|c|c|c|c|c|c|c|}
\hline \multirow[b]{2}{*}{ Período } & \multicolumn{2}{|c|}{ Vazão $\left(\mathrm{m}^{3} \mathrm{~s}^{-1}\right)$} & \multicolumn{2}{|c|}{ Vazão (mm) } & \multirow{2}{*}{$\begin{array}{c}\text { Precipitação } \\
\text { mm }\end{array}$} & \multirow{2}{*}{$\begin{array}{l}\mathrm{ET}^{1} \\
\mathrm{~mm}\end{array}$} & \multirow{2}{*}{$\begin{array}{r}\text { Consumo } \\
\mathrm{m}^{3} \mathrm{ha}^{-1}\end{array}$} \\
\hline & Irrig. & Dren. & Irrig. & Dren. & & & \\
\hline $01-10 / 09 / 08$ & 0,320 & 0,000 & 10,0 & 0,0 & 0,000 & 51,0 & 100,0 \\
\hline $11-20 / 09 / 08$ & 2,180 & 0,000 & 68,3 & 0,0 & 48,6 & 49,6 & 683,0 \\
\hline $21-30 / 09 / 08$ & 1,831 & 0,150 & 57,1 & 4,7 & 28,1 & 41,4 & 524,0 \\
\hline 01-10/10/08 & 2,294 & 0,115 & 71,6 & 3,6 & 13,1 & 43,1 & 680,0 \\
\hline $11-20 / 10 / 08$ & 1,836 & 1,165 & 57,3 & 36,3 & 111,5 & 46,0 & 209,0 \\
\hline $21-31 / 10 / 08$ & 1,906 & 1,295 & 65,4 & 44,4 & 146,3 & 41,5 & 210,0 \\
\hline 01-10/11/08 & 1,926 & 0,933 & 60,1 & 29,1 & 59,8 & 61,4 & 310,0 \\
\hline $11-20 / 11 / 08$ & 1,468 & 1,190 & 45,8 & 37,1 & 76,0 & 36,4 & 87,0 \\
\hline $21-30 / 11 / 08$ & 1,380 & 1,240 & 43,0 & 38,7 & 113,3 & 51,8 & 44,0 \\
\hline $01-10 / 12 / 08$ & 1,801 & 0,075 & 56,2 & 2,3 & 29,5 & 65,6 & 538,0 \\
\hline $11-20 / 12 / 08$ & 1,733 & 1,079 & 54,1 & 33,7 & 89,9 & 33,5 & 204,0 \\
\hline $21-31 / 12 / 08$ & 1,818 & 0,342 & 62,4 & 11,7 & 17,7 & 78,0 & 506,0 \\
\hline 01-10/01/09 & 1,416 & 1,359 & 44,2 & 42,4 & 248,8 & 74,4 & 18,0 \\
\hline $11-20 / 01 / 09$ & 1,628 & 0,463 & 50,8 & 14,5 & 67,1 & 41,4 & 363,0 \\
\hline $21-31 / 01 / 09$ & 1,610 & 0,696 & 55,2 & 23,9 & 91,0 & 61,7 & 314,0 \\
\hline $01-10 / 02 / 09$ & 1,707 & 1,206 & 53,2 & 37,6 & 149,0 & 53,3 & 156,0 \\
\hline $11-20 / 02 / 09$ & 1,130 & 0,974 & 35,2 & 30,4 & 91,9 & 49,7 & 49,0 \\
\hline $21-28 / 02 / 09$ & 1,028 & 0,885 & 25,6 & 22,1 & 113,1 & 40,9 & 35,0 \\
\hline Média & 1,707 & 0,775 & - & - & - & - & - \\
\hline Total & - & - & 915,5 & 412,5 & 1494,7 & 869,7 & 5030 \\
\hline
\end{tabular}

${ }^{1}$ ET- Evapotranspiração

Tabela 2. Dados do consumo de água na área da Adisi na safra 2009/2010. 


\begin{tabular}{|c|c|c|c|c|c|c|c|}
\hline \multirow[b]{2}{*}{ Período } & \multicolumn{2}{|c|}{ Vazão $\left(\mathrm{m}^{3} \mathrm{~s}^{-1}\right)$} & \multicolumn{2}{|c|}{ Vazão (mm) } & \multirow{2}{*}{$\begin{array}{c}\text { precipitação } \\
\text { mm }\end{array}$} & \multirow{2}{*}{$\begin{array}{l}\mathrm{ET}^{1} \\
\mathrm{~mm}\end{array}$} & \multirow{2}{*}{$\begin{array}{c}\text { Consumo } \\
\mathrm{m}^{3} \mathrm{ha}^{-1}\end{array}$} \\
\hline & Irrig. & Dren. & Irrig. & Dren. & & & \\
\hline & 1,364 & 0,835 & 42,5 & 26,1 & 39,2 & 34,2 & 165 \\
\hline $11-20 / 09 / 09$ & 1,670 & 1,535 & 52,1 & 47,9 & 45,4 & 34,9 & 42 \\
\hline $21-30 / 09 / 09$ & 1,734 & 1,128 & 54,1 & 35,2 & 164,7 & 36,6 & 189 \\
\hline 01-10/10/09 & 1,883 & 0,974 & 58,7 & 30,4 & 50,9 & 37,3 & 284 \\
\hline $11-20 / 10 / 09$ & 1,911 & 1,025 & 59,6 & 32,0 & 155,0 & 41,3 & 277 \\
\hline $21-31 / 10 / 09$ & 1,927 & 0,529 & 66,1 & 18,1 & 189,0 & 42,1 & 480 \\
\hline 01-10/11/09 & 1,897 & 0,325 & 59,2 & 10,1 & 147,4 & 43,7 & 490 \\
\hline $11-20 / 11 / 09$ & 1,608 & 1,282 & 50,2 & 40,0 & 148,8 & 43,8 & 102 \\
\hline $21-30 / 11 / 09$ & 2,155 & 0,647 & 67,2 & 20,2 & 56,4 & 44,5 & 470 \\
\hline $01-10 / 12 / 09$ & 2,218 & 0,396 & 69,2 & 12,4 & 44,2 & 49,1 & 568 \\
\hline $11-20 / 12 / 09$ & 2,124 & 0,785 & 66,2 & 24,5 & 87,3 & 50,5 & 418 \\
\hline $21-31 / 12 / 09$ & 2,218 & 0,780 & 76,1 & 26,8 & 31,5 & 52,2 & 493 \\
\hline $01-10 / 01 / 10$ & 2,024 & 1,485 & 63,1 & 46,3 & 100,4 & 54,1 & 168 \\
\hline $11-20 / 01 / 10$ & 1,924 & 1,049 & 60,0 & 32,7 & 54,3 & 56,8 & 273 \\
\hline $21-31 / 01 / 10$ & 1,982 & 1,541 & 68,0 & 52,9 & 48,2 & 57,4 & 151 \\
\hline $01-10 / 02 / 10$ & 2,157 & 1,171 & 67,3 & 36,5 & 113,3 & 61,1 & 307 \\
\hline $11-20 / 02 / 10$ & 1,559 & 1,956 & 48,6 & 61,0 & 194,2 & 65,8 & -124 \\
\hline $21-28 / 02 / 10$ & 1,144 & 1,143 & 28,5 & 28,5 & 24,2 & 67,1 & 0 \\
\hline Média & 1,861 & 1,033 & - & - & - & - & - \\
\hline Total & - & - & 1056,8 & 581,5 & 1694,4 & 872,42 & 4753 \\
\hline
\end{tabular}

${ }^{1}$ ET - Evapotranspiração

Para a área de 2770 ha a vazão média do ano de 2008/2009 foi de $0,61 \mathrm{~L} \mathrm{~s}^{-1} \mathrm{ha}^{-1}$ e no ano 2009/2010 correspondeu a $0,67 \mathrm{~L} \mathrm{~s}^{-1} \mathrm{ha}^{-1}$. A maior vazão derivada correspondeu a $0,80 \mathrm{~L} \mathrm{~s}^{-}$ ${ }^{1} \mathrm{ha}^{-1}$. Nos projetos de irrigação de arroz normalmente adota-se como necessidades de água valores superiores a 1,0 $\mathrm{L} \mathrm{s}^{-1} \mathrm{ha}^{-1}$ (CASAN/MAGNA, 1995; EPAGRI 2000). Os valores inferiores obtidos nesse trabalho se devem em parte ao fato de ter sido dois anos com chuvas excessivas e também pelo fato de estar sendo considerado um período de irrigação de 181 dias, superior ao período de cultivo que varia de 120 a 150 dias, dependendo da cultivar. Esse período de 181 dias se deve ao fato da semeadura ter ocorrido no período de 15 de setembro a 15 de novembro ( $35 \%$ em setembro, $53 \%$ em outubro e $12 \%$ em novembro). Com um controle 
mais eficiente da irrigação evitando os excessos e com a adoção de um escalonamento planejado do plantio dentro da época de plantio recomendada na região pode-se melhorar a eficiência do sistema e ainda obter vazões médias inferiores as obtidas neste trabalho. De acordo com Louzada (2004), a preocupação com a definição de parâmetros de consumo na irrigação por inundação no Rio Grande do Sul existe desde meados da década de 50. A partir desta data, o IRGA passou a recomendar vazões entre 1,7 e $3,0 \mathrm{~L} \mathrm{~s}^{-1} \mathrm{ha}^{-1}$, valores que persistiram por 40 anos. A partir da década de 90 as vazões recomendadas estão entre 1,5 e 2,0 $\mathrm{L} \mathrm{s}^{-1} \mathrm{ha}^{-1}$ (IRGA, 1996), o que foi possível com o avanço da tecnologia proporcionado pela pesquisa associado a maior conscientização dos agricultores (CORRÊA et al., 1997). Durante e após este período, vários experimentos de campo, em áreas experimentais, já foram conduzidos com o objetivo de medir o consumo em áreas cultivadas com arroz irrigado por inundação. Trabalhos realizados por Back e Rosso (2007), avaliando a necessidade de água para irrigação do arroz no cultivo pré-germinado nas condições climáticas do sul de Santa Catarina, mostraram que as exigências variam de acordo com os estádios da cultura. Os maiores valores de vazão são necessários na fase de preparo do solo, com valores variando de 1,005 a 1,158 $\mathrm{L} \mathrm{s}^{-1} \mathrm{ha}^{-1}$. Para os solos sem perdas por percolação a vazão média é de $0,472 \mathrm{~L} \mathrm{~s}^{-}$ ${ }^{1} \mathrm{ha}^{-1}$ na fase vegetativa, $0,263 \mathrm{~L} \mathrm{~s}^{-1} \mathrm{ha}^{-1}$ na fase reprodutiva e $0,177 \mathrm{~L} \mathrm{~s}^{-1} \mathrm{ha}^{-1}$ na fase de maturação. Beltrame e Louzada (1991) estimaram o consumo de água para o arroz irrigado em diferentes regiões do Rio Grande do Sul, obtendo vazões variando de 1,56 $\mathrm{L} \mathrm{s}^{-1}$ ha $^{-1}$ até 1,76 $\mathrm{L} \mathrm{s}^{-1} \mathrm{ha}^{-1}$ e a vazão média varia de $1,32 \mathrm{~L} \mathrm{~s}^{-1} \mathrm{ha}^{-1}$ a $1,54 \mathrm{~L} \mathrm{~s}^{-1} \mathrm{ha}^{-1}$, porém não foi considerado a contribuição da precipitação efetiva.

No ano 2008/2009 no período de 181 dias foi irrigado o equivalente a 915,5 $\mathrm{mm}$ e drenagem foi de 412,4 mm, sendo a diferença equivalente ao consumo de água de 503,0 mm. No ano 2009/2010 a irrigação foi de $1056,8 \mathrm{~mm}$ e a drenagem $584,5 \mathrm{~mm}$, com consumo de 475,3 mm. Com esses dados observa-se que a eficiência da irrigação foi de 54,9 \% e 45,0\%. Essa eficiência pode ser aumentada com um controle mais rigoroso na entrada de água.

No 2008/2009 durante o período de irrigação foram registrados 1494,7 mm de precipitação e 920,6 mm de evapotranspiração. Para o ano de 2009/2010 esses valores foram respectivamente de $1694,4 \mathrm{~mm}$ e $874,4 \mathrm{~mm}$. A evapotranspiração média foi de respectivamente 5,1 e $4,8 \mathrm{~mm} \mathrm{dia}^{-1}$, concordando com os valores de 4 a $7 \mathrm{~mm} \mathrm{dia}^{-1}$ citados por Tsutsui (1972) e De Datta et al. (1975). Esses dados reforçam a observação de Rosso (2007) que grande parte da demanda da água é suprida pela precipitação e a irrigação tem papel suplementar para o atendimento da demanda. Para um melhor aproveitamento da água 
da precipitação é importante a adoção e manutenção de taipas altas de maneira a possibilitar maior acúmulo de água, conforme recomendados por Epagri (2000), Macedo et al. (2007), Sosbai (2014),

Os valores de consumo de água nos dois anos na área de 2770 ha foram respectivamente de $5030 \mathrm{~m}^{3} \mathrm{ha}^{-1}$ e $4753 \mathrm{~m}^{3} \mathrm{ha}^{-1}$. Esses valores são inferiores aos valores de consumo de água citados nos trabalhos de Eberhardt (1994), Marcolin e Macedo (2001), Machado et al. (2002), Machado (2003), Back e Rosso (2007), que encontraram valores entre de $6000 \mathrm{~m}^{3} \mathrm{ha}^{-1}$ e $9000 \mathrm{~m}^{3} \mathrm{ha}^{-1}$. Essa diferença pode ser explicada pela grande contribuição da chuva e também pelo fato de que em sistemas coletivos, as propriedades localizadas à jusante aproveitarem a água drenada das propriedades à montante. A maioria dos trabalhos sobre o consumo de água são realizados em parcelas experimentais ou a nível de propriedade. Em um sistema coletivo de irrigação como a área da Adisi, as perdas por infiltração lateral e perdas por drenagem são menos significativas e parte da água perdida por infiltração e escoamento em uma área retorna ao sistema de irrigação e drenagem sendo reaproveitada nas áreas à jusante.

\section{Conclusões}

Com base nas observações do monitoramento realizado durante dois ciclos de cultivo pode-se concluir que a eficiência do sistema de irrigação variou de 45 a 55\%, e a adoção de medidas de controle da irrigação pode aumentar a eficiência do sistema de drenagem. A irrigação durante o período de 181 teve como vazão máxima $0,8 \mathrm{~L} / \mathrm{s}$ ha e vazão média de 0,62 a $0,67 \mathrm{~L} \mathrm{~s}^{-1} \mathrm{ha}^{-1}$. O consumo de água de irrigação foi equivalente a 4753 e $5030 \mathrm{~m}^{3} \mathrm{ha}^{-1}$.

\section{Referências}

BACK, Á. J. Hidráulica e Hidrometria Aplicada (com programa Hidrom para cálculo). Florianópolis: Epagri, 2015. 398p.

BACK, Á. J.; ROSSO, J. C. Balanço Hídrico na cultura do arroz irrigado no sistema prégerminado In: CONGRESSO BRASILEIRO DE ENGENHARIA AGRÍCOLA, 36., 2007, Bonito, MS. Anais... Jaboticabal: SBEA, 2007. p.1 - 4

BELTRAME, L. S.; LOUZADA, J. 1991. A water use rationalization in rice irrigation by flooding. In : INTERNATIONAL SEMINAR ON EFFICIENT WATER USE. Cidade do México, 1991. Anais ... Cidade do México.1991. p.337-345.

CASAN; MAGNA. Estudo de Impacto Ambiental, Barragem do Rio São Bento. Siderópolis, SC, 1995. 223p.

CORRÊA, N. et al. Consumo de água na irrigação do arroz por inundação. Lavoura Arrozeira, Porto Alegre, v.50, n.432, 1997. p.3-8.

De DATTA, S. K. et al. Manejo del água y necessidades de riego del arroz. Quezon City, Universidade of the Philippines, 1975. p.121-127. 
EBERHARDT, D. S. Consumo de água em lavoura de arroz irrigado sob diversos métodos de preparo do solo. Agropecuária Catarinense. Florianópolis. v.7, n. 1, p. 51-53, mar. 1994. EMBRAPA CLIMA TEMPERADO. Cultivo do Arroz Irrigado no Brasil: Importância Econômica, Agrícola e Alimentar do Arroz, 2005. Disponível em: http://sistemasdeproducao.cnptia.embrapa.br/FontesHTML/Arroz/ArrozIrrigadoBrasil/cap01. htm.

EPAGRI. Barragem do Rio do Salto: Estudo de Impacto Ambiental (EIA). Florianópolis, 2000. 380p.

FERNANDES, V. S. Manejo de água contínuo no cultivo do arroz irrigado no sistema pré-germinado. 2004. 88f. Dissertação (Mestrado em Agroecossistemas) - Universidade Federal de Santa Catarina, Centro de Ciências Agrárias, Florianópolis.

FREITAS, C. Mãos dadas pela produtividade da lavoura. Revista agropecuária catarinense, v.22, n.2, p.31-33, 2009.

FGV. Revista de Economia Agrícola da FGV - AGROANALYSIS. Vol. 18, nº

3. 1998. 80p.

IRGA. Manejo da água e da adubação para maior sustentabilidade da lavoura de arroz pré-germinado no RS. IRGA, Boletim Técnico 3. Cachoeirinha, RS, 2007.

Sociedade Sul Brasileria de Arroz Irrigado (SOSBAI). Arroz Irrigado: Recomendações Técnicas da Pesquisa para o Sul do Brasil. 3.ed. Cachoeirinha, 1996. 88p.

LADWIG, N.I.; SILVA, E. P. da. A cobrança do uso da água de o impacto no custo da produção do arroz irrigado na região sul do Estado de Santa Catarina. Boletim Geográfico, v.45, n.2, p.31-44, 2017.

LOUZADA, J. A. Simulação da irrigação por inundação e da drenagem nos solos de várzea do Rio Grande do Sul . Tese (Doutorado em Engenharia) - Programa de PósGraduação em Engenharia de Recursos Hídricos e Saneamento Ambiental da Universidade Federal do Rio Grande do Sul. 2004

MACEDO, V. R. M. et al. Manejo da água e da adubação para maior sustentabilidade. Cachoeirinha: IRGA. Divisão de pesquisa, 2007. 20 p. Boletim Técnico, 3.

MACHADO, S. L. O. Sistemas de estabelecimento do arroz irrigado, consumo de água e perdas de nutrientes na água de drenagem inicial, monitoramento de herbicidas na água da lavoura e efeitos no jundiá. 2003. Tese (Doutorado) - Universidade Federal de Santa Maria.

MARCOLIN, E.; MACEDO, V. R. M. Consumo de água em três sistemas de cultivo de arroz irrigado. In: CONGRESSO NACIONAL DE IRRIGAÇÃO E DRENAGEM, 11, 2001, Fortaleza, CE. Anais... Fortaleza: CONIRD, 2001. p.59-63.

MACHADO, S. L. et al. Consumo de água em cinco sistemas de cultivo do arroz irrigado. In: Congresso da Cadeia Produtiva de Arroz, $1^{\circ}$; e Reunião Nacional de Pesquisa de Arroz (RENAPA), 7ª , 2002, Florianópolis. Anais, 2002. v.1. p.336-339.

MOTTA, F. S. et al. Informação climática para planejamento da necessidade de água para irrigação do arroz no Rio Grande do Sul. Lavoura Arrozeira. Porto Alegre, v. 43, n. 392, p. 3-6, 1990.

NOGUEIRA, M.G.; NOGUEIRA, M. G.; HENRY, R.; JORCIN, A. (Orgs.). Ecologia de reservatórios: impactos potenciais, Ações de manejo e Sistemas em cascata. 2 ed. São Paulo: Rima, 2006. 459 p.

ROSSO, J. C. Avaliação do consumo de água em lavouras de arroz irrigado no sistema pré-germinado nas condições climáticas do Sul Catarinense. 2007.67f. Dissertação (Mestrado em Ciências Ambientais) - Programa de Pós-Graduação em Ciências Ambientais, Universidade do Extremo Sul Catarinense.

SANTOS, F. S. et al. Manejo racional da água de irrigação no sistema de cultivo prégerminado. In : CONGRESSO DE INICIAÇÃO CIENTÍFICA, 16., 2007,Pelotas, RS. 
Anais... Pelotas: Pró-reitoria de Pesquisa e Pós-Graduação, 2007. Disponível em: http://www.ufpel.tche.br/cic/2007/cd/pdf/CA/CA_00295.pdf

SOCIEDADE SUL-BRASILEIRA DE ARROZ IRRIGADO -SOSBAI. Arroz Irrigado: Recomendações técnicas da Pesquisa para o Sul do Brasil; In: XXX Reunião técnica da cultura do arroz irrigado. Sosbai, Santa Maria, 2014. 192p.

STONE, L. F. Eficiência do uso da água na cultura do arroz irrigado. Embrapa Arroz e Feijão, 2005. 176p.

TABBAL, D. F.; BOUMAN, B. A. M.; BHUIYAN, S. I.; SIBAYAN, E. B.; SATTAR, M. A. On-farm strategies for reducing water input in irrigated rice: case studies in the Philippines. Agricultural Water Management, Amsterdam, v. 56, n. 2, p. 93-112, July 2002.

TSUSUI, H. Manejo de água para a produção de arroz. Lavoura Arrozeira, Porto Alegre, v. 23 , n.268, p. 24-27,1972.

\section{Agradecimentos}

Os autores agradecem a Fundação de Apoio à Pesquisa Científica e Tecnológica do Estado de Santa Catarina (FAPESC) pelo apoio financeiro a esta pesquisa. 